\title{
Emergency planning and optimizations based on dam break flood risk maps visualized with open source web-GIS tool
}

\author{
Nina Dobrinkova, Stefan \\ Stefanov, Stefan Hadjitodorov \\ Institute of Information and \\ Communication Technologies - \\ BAS, Bulgaria \\ Email:ninabox2002@gmail.com, \\ stefans.stefanov303@gmail.com \\ Center for National Security and \\ Defence Research, Bulgaria \\ Email: sthadj@cu.bas.bg
}

\author{
Alexander Arakelyan, Alen \\ Amirkhanian, Ara Barseghyan, \\ Susan Mnatsakanian \\ American University in Armenia \\ Email: \\ alexander.arakelyan@aua.am, \\ alen@aua.am \\ Ministry of Emergency Situations \\ in Armenia
}

\author{
George Drakatos, Christos \\ Evangelidis, Vangelis Katsaros, \\ George Boustras \\ National Observatory of Athens - \\ Greece, Email: g.drakat@noa.gr, \\ cevan@noa.gr \\ European University Cyprus - \\ Cyprus, Email: \\ ekatsaro@gmail.com, \\ g.boustras@euc.ac.cy
}

\begin{abstract}
Nowadays technologies are changing every day and with them all services and tools in cases of disaster situations increase. However some sectors such as emergency planning and response are still having difficulties to implement the new technologies. In our paper we will present an idea on how new technologies in flood risk mapping visualization can give more options to the first responders and optimize their time for reaction. The test area is located in Armenia, where exist a special dam constructed for mining purposes. It is built in earthquake vulnerable area and we evaluate the risk of dam break at that location. The final results which are flood risk maps are implemented in specially developed open source webGIS tool. This tool is applicable for decision making in operational room or any other first responder facilities.
\end{abstract}

\section{INTRODUCTION}

$\mathrm{T}$ HE Alliance for Disaster Risk Reduction project (ALTER project) has been designed in the framework of DG ECHO external line call. These types of projects have as main goal to address cooperation between EU and third party countries. Main idea is best practices transfer from EU to external neighboring country. In ALTER project that selected country is Armenia. The project has as main objective to create public private partnerships to increase resilience in areas of Armenia that face risks from floods originating in earthquakes. Methods, tools, know how and experience from Greece, Bulgaria and Cyprus have been shared with Armenian partners. The partnership of the Armenian government and local stakeholders gave an opportunity to the consortia to work on larger scale at the selected test areas. The project is focused on three pilot areas in Armenia where dams and other activities such as mining processes are presenting the risks to local communities. The areas are: Akhtala and Teghut areas of Lori Marz along the Shamlugh river; the Vorotan Cascade and its associated dams in the Syunik region; and the Voghji river basin of Syunik region. In the paper will be presented

This work has been supported by the DG ECHO project called: "Alliance for disaster Risk Reduction in Armenia" with acronym: ALTER and Grand Number: 783214. information about the Armenian study area. Data that has been collected for dams at this study area. Calculations about potential dam failure and possible flood risk maps. As a final section will be summarized a specifically developed open source web-GIS tool and its main functionalities. The purpose of the web tool is to support a decision making on the field and to optimize resources allocation.

\section{STUDY AREA}

One of the activities of the project ALTER was to identify the most suitable best practices on risks related to dams in earthquake zones available within and outside the consortia. The study area selected for Armenia was: Kapan and Voghji River Basin. This area is located about $300 \mathrm{~km}$ southeast of Yerevan and has a population of about 45,000 . It contains some of Armenia's most intensive mining activities and two of Armenia's largest tailing dams Artsvanik and Geghanush. Additionally, the Geghi Reservoir upstream of Kapan were also included. The villages Kavchut, Andiokavan, Hamletavan, Shgharjik, Syunik and the Kapan Town are located in the immediate floodplain of the Geghi and Voghji Rivers. The village of Verin Giratagh and Nerkin Giratagh are not in the floodplain, however the only road access to these villages is through the floodplain below the Geghi dam. The two tailing dams also pose risk to Kapan's airport which would be needed in case of an emergency and the main highway connecting Armenia and Iran.

The Geghi reservoir is located in Syunik, the southernmost province of Armenia (Figure 1). The reservoir is situated on the Geghi river, the left-bank tributary of the river Voghji. The maximum water level discharge occurs during the spring. Due to the high altitude nature of the area, snowmelt increases gradually as does the level of the river and the reservoir. Snowmelt typically occurs from March to August (Armenian State Hydrometeorological and Monitoring Service). 


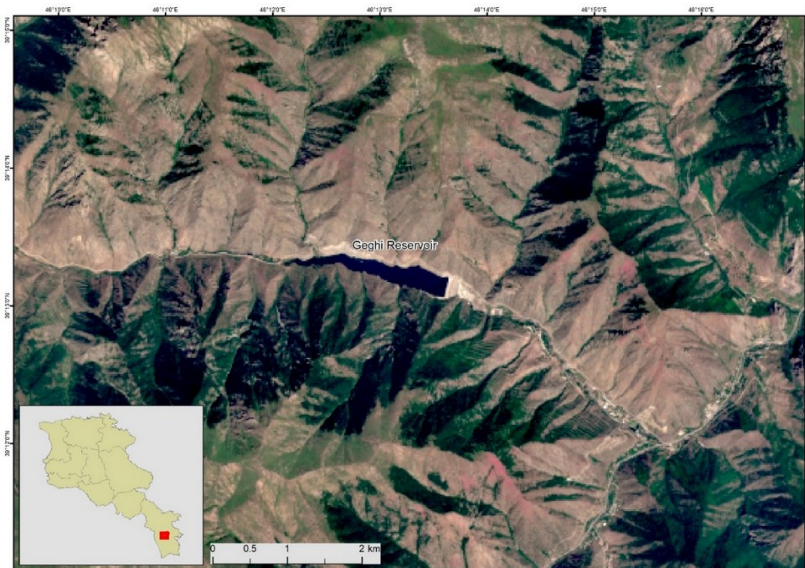

Figure 1. The location of Geghi reservoir. The inset shows its location within Armenia. Background image: Sentinel-2, RGB composite.

The surface of the Geghi reservoir is 50 ha and the elevation above sea level is nearly $1400 \mathrm{~m}$. The height of the dam is $70 \mathrm{~m}$ and the length along the crest is $270 \mathrm{~m}$. The total volume of reservoir is 15 million $\mathrm{m}^{3}$, but the effective volume is about 12 million $\mathrm{m}^{3}$ [1]. Nearly 4,300 people would be affected by a dam break affecting the reservoir [2]. Geghanoush Tailing Storage Facility (TSF)

Geghanoush TSF is located in the gorge of the Geghanoush River, in the southern part of Kapan (Figure 2). The difference of relative heights between the tailing dam, on one hand, and city buildings and transport infrastructure, on the other hand, is 75 meters. In case the reservoir dam is broken due to an earthquake, the sliding mass could cover industrial and residential buildings, and as a result of barrage, the polluted water could flood central quarters of the city.

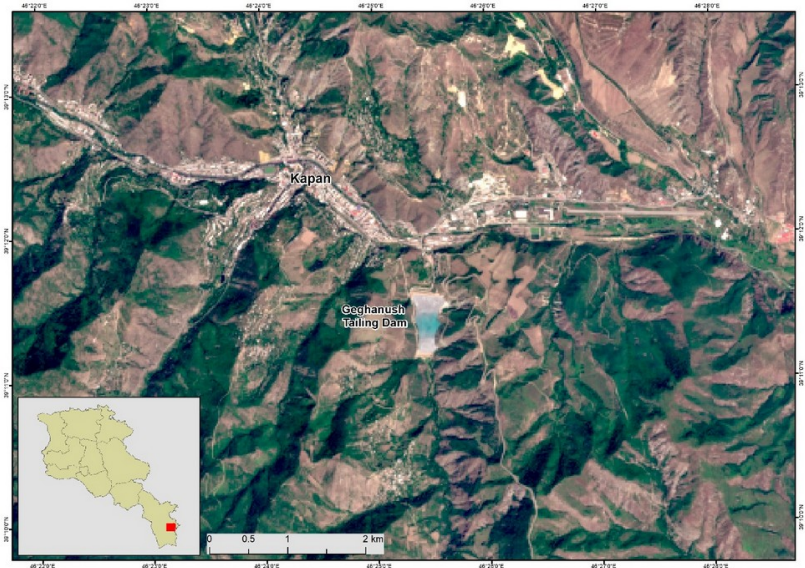

Figure 2. The location of Geghanush Tailing Dam. The inset shows its location within Armenia. Background image: Sentinel-2, RGB composite.

The existing Geghanoush Tailings Repository was designed in early 1960's and had been operated between 1962 and 1983, when the Kajaran Tailings Repository at Artsvanik was commissioned. The Geghanoush tailings repository was re-commissioned in 2006 after the completion of the diversion works and continues to be used today along with an upstream extension currently under construction. The volume of the tailing is 5.4 million $\mathrm{m}^{3}$ and the dam height is $21.5 \mathrm{~m}[1]$.

Tailing and water dams in the appointed pilot area are hazardous hydro-technical structures because of their location in earthquake prone zone. In addition, dam break could occur due to the technical condition of the dams and improper exploitation. Catastrophic flood are possible in this place caused by dam failure. Therefore, the assessment of dam break consequences has a crucial meaning for emergency management and development for measures and action plans for stakeholders and respective authorities in Armenia.

\section{METHODOLOGY AND DATA USED}

\section{A. Methodology}

Flood modeling basics refer to 1D and 2D models, which provide steady and unsteady flows, including the necessity of Manning $\mathrm{N}$ values usage.

There are many event types and phenomena that can lead to dam failure:

- Flood event

- Landslide

- Earthquake

- Foundation failure

- Structural failure

- $\quad$ Piping/seepage (internal and underneath the dam)

- Rapid drawdown of pool

- Planned removal

- Terrorism act

Given the different mechanisms that cause dam failures, there can be several possible ways dam may fail for a given driving force/mechanism. In 1985 and in 2002 has been analyzed a list of dam types $[3,4]$ versus possible modes of failure.

The reports from 1985 noticed that of all dam failures $34 \%$ were caused by overtopping, 30\% due to foundation defects, $28 \%$ from piping and seepage, and $8 \%$ from other modes of failure. In the same report of dam failures are included earth/embankment dams, for which $35 \%$ have failed due to overtopping, $38 \%$ from piping and seepage, $21 \%$ from foundation defects, and $6 \%$ from other failure modes.

In our work we are doing analysis of a potential dam failure. The prediction of the reservoir outflow hydrograph and the routing of that hydrograph through the downstream valley are evaluated to determine dam failure consequences. There are calculated results about the risk of the population located close to the dam, it is important to accurately predict the breach outflow hydrograph and its timing relative to 
events in the failure process that could trigger the start of evacuation efforts [5].

\section{B. Hydro-meteorological Observation Data}

Hydro-meteorological Observation Data Flood formation and its behavior is highly dependent from hydro-meteorological conditions of the territory. Rainfall intensity and duration, snowmelt, air temperature and other meteorological factors are key drivers in flood development process. Hydro-meteorological monitoring within the territory of Armenia is conducted by Hydromet Service of the Ministry of Emergency Situations of Armenia.

There are 2 operational meteorological stations within Voghji River Basin: Kajaran and Kapan providing

\begin{tabular}{|c|c|c|c|c|c|}
\hline № & $\begin{array}{c}\text { Name of } \\
\text { Station }\end{array}$ & Latitude & Longitude & $\mathbf{H}, \mathbf{m}$ & $\begin{array}{c}\text { Observation } \\
\text { Period }\end{array}$ \\
\hline 1 & Kajaran & $39^{\circ} 09^{\prime} 10^{\prime \prime}$ & $46^{\circ} 09^{\prime} 33^{\prime \prime}$ & 1843 & $1975-$ present \\
\hline 2 & Kapan & $39^{\circ} 12^{\prime} 15^{\prime \prime}$ & $46^{\circ} 27^{\prime} 44^{\prime \prime}$ & 705 & $1936-$ present \\
\hline
\end{tabular}

information. Their location is presented in table 1 .

\section{Table 1. Operational Monitoring Stations within Voghji River} Basin

Thermal conditions normally decrease in the Voghji Basin as altitude increases. Multiyear annual average air temperature is in Kajaran is $6.8^{\circ} \mathrm{C}$ and in Kapan is $12.3^{\circ} \mathrm{C}$ (Table 2).

Table 2. Annual and monthly average air temperatures in the

Voghji River Basin, oC

\begin{tabular}{|c|c|c|c|c|c|c|c|c|c|c|c|c|c|c|}
\hline \multirow{2}{*}{$\begin{array}{l}\text { Meteorological } \\
\text { Station }\end{array}$} & \multirow{2}{*}{$\begin{array}{l}\text { Absolute } \\
\text { Altitude } \\
\text { (m) }\end{array}$} & \multicolumn{12}{|c|}{ Month } & \multirow{2}{*}{$\frac{1}{d}$} \\
\hline & & I & II & III & IV & V & VI & VII & VIIII & IX & $x$ & $\mathrm{XI}$ & $X \|$ & \\
\hline Kajaran & 1980 & -3.4 & -3.0 & 0.5 & 5.7 & 10.2 & 14.2 & 17.1 & 16.6 & 13.3 & 8.2 & 32 & 1.0 & 6.8 \\
\hline Kapan & 704 & 0.8 & 2.4 & 6.3 & 12.3 & 16.1 & 20.4 & 23.7 & 23.1 & \begin{tabular}{|l|l|}
19.0 \\
\end{tabular} & 130 & 7.5 & 2.9 & 12.3 \\
\hline
\end{tabular}

Rainfall generally increases by altitude in the basin (table 3 ).

Table 3. Intra-annual distribution of atmospheric precipitation in the Voghji River Basin, $\mathrm{mm}$

\begin{tabular}{|c|c|c|c|c|c|c|c|c|c|c|c|c|c|c|}
\hline \multirow{2}{*}{$\begin{array}{l}\text { Meteorological } \\
\text { station }\end{array}$} & \multirow{2}{*}{$\begin{array}{l}\text { Absolute } \\
\text { Altitude } \\
\text { (m) }\end{array}$} & \multicolumn{12}{|c|}{ Month } & \multirow{2}{*}{$\frac{8}{2}$} \\
\hline & & 1 & $\|$ & III & IV & V & $\mathrm{VI}$ & VII & VIII & IX & $x$ & $\mathrm{X} \mid$ & XII & \\
\hline Kajaran & 1980 & 44 & 51 & 74 & 84 & 85 & 49 & 23 & 21 & 31 & 52 & 49 & 41 & 605 \\
\hline Kapan & 704 & 25 & 31 & 59 & 75 & 94 & 66 & 31 & 28 & 41 & 49 & 40 & 25 & 565 \\
\hline
\end{tabular}

The average annual relative humidity is $50-60 \%$, and less than $30 \%$ at low altitudes (up to $1000 \mathrm{~m}$ ). Frost-free days vary by altitude - annually from 260 (at the altitude of 700 $\mathrm{m})$ to 50 days (higher than $3000 \mathrm{~m}$ ). The annual average relative humidity is $60-80 \%$ (over $2600 \mathrm{~m}$ ), and at lower altitudes - up to $30 \%$ (up to $1000 \mathrm{~m}$ ).

Permanent snow cover starts at altitudes of $1200 \mathrm{~m}$ and it lasts for 35-165 days. The snow depth is $15-180 \mathrm{~cm}$. It lasts 1-1.5 months at altitudes of up to $1500 \mathrm{~m}$, and 6.5-7 months at altitudes of $3000 \mathrm{~m}$ and higher. The depth of snow cover is $15-20 \mathrm{~cm}$ at altitudes of $1300-1500 \mathrm{~m}$ and $120-180 \mathrm{~cm}$ at altitudes of $3000 \mathrm{~m}$ and higher (from place to place a 300 $\mathrm{cm}$ thick snow cover is formed, due to winds occurring in concavities).

Evaporation drops to $482-220 \mathrm{~mm}$ as altitude increases in the Voghji River Basin. The highest value of evaporation, $500-480 \mathrm{~mm}$, is observed at altitudes up to $800 \mathrm{~m}$.

There are 3 operational hydrological monitoring posts within Voghji River Basin: Voghji-Kajaran, Voghji-Kapan and Geghi-Kavchut. Data of closed monitoring posts of Geghi-Geghi and Geghanoush-Geghanoush were analyzed as well due to their importance for the Geghi reservoir and Geghanoush tailings dam break modeling (tables 4 and 5).

Table 4. Hydrological Monitoring Posts within Voghji River Basin

\begin{tabular}{|r|l|l|c|c|}
\hline \multirow{2}{*}{ № } & \multirow{2}{*}{$\begin{array}{c}\text { Water Object } \\
\text { Name }\end{array}$} & \multirow{2}{*}{ Name of station } & \multicolumn{2}{|c|}{ Coordinates } \\
\cline { 4 - 5 } & & Latitude & Longitude \\
\hline 1 & Voghji River & Kajaran & $39^{\circ} 08^{\prime} 59^{\prime \prime}$ & $4609^{\prime} 16^{\prime \prime}$ \\
\hline 2 & Voghji River & Kapan & $39^{\circ} 12^{\prime} 18^{\prime \prime}$ & $4624^{\prime} 43^{\prime \prime}$ \\
\hline 3 & Geghi River & Kavchut & $39^{\circ} 12^{\prime} 23^{\prime \prime}$ & $4614^{\prime} 50^{\prime \prime}$ \\
\hline 4 & Geghi River & Geghi & $39^{\circ} 13^{\prime} 21^{\prime \prime}$ & $469^{\prime} 36^{\prime \prime}$ \\
\hline 5 & $\begin{array}{l}\text { Geghanoush } \\
\text { River }\end{array}$ & Geghanoush & $39^{\circ} 10^{\prime} 35^{\prime \prime}$ & $4625^{\prime} 24^{\prime \prime}$ \\
\hline
\end{tabular}

Table 5. Flow Characteristics in the Hydrological Monitoring Posts within Geghi River Basin

\begin{tabular}{|c|c|c|c|c|c|c|c|c|c|c|c|c|c|c|}
\hline \multirow{2}{*}{ River-Post } & I & II & III & IV & V & VI & VII & VIII & IX & X & XI & XII & $\begin{array}{c}\text { Annual } \\
\text { Average }\end{array}$ & Maximum \\
\hline Geghi-Geghi & 1.5 & 1.5 & 1.9 & 5.5 & 12.7 & 12.9 & 6.9 & 3.3 & 2.3 & 2.0 & 1.8 & 1.6 & 4.5 & 37.7 \\
\hline Geghi-Kavchut & 1.4 & 1.5 & 2.3 & 5.9 & 12.5 & 12.0 & 6.3 & 3.0 & 2.1 & 1.9 & 1.7 & 1.5 & 4.4 & 87.5 \\
\hline Geghanoush-Geghanoush & 0.2 & 0.2 & 0.7 & 1.9 & 1.8 & 0.9 & 0.4 & 0.3 & 0.3 & 0.3 & 0.3 & 0.2 & 0.6 & 21.3 \\
\hline Voghji-Kajaran & 0.5 & 0.5 & 0.8 & 3.0 & 7.7 & 11.5 & 7.2 & 2.5 & 1.0 & 0.7 & 0.6 & 0.5 & 3.0 & 43.9 \\
\hline Voghji-Kapan & 2.4 & 2.6 & 4.6 & 14.5 & 28.7 & 28.5 & 15.6 & 6.4 & 3.9 & 3.6 & 3.2 & 2.7 & 9.7 & 270.0 \\
\hline
\end{tabular}

\section{A. Elevation Data}

Elevation data has a crucial meaning in each flood modeling process. There are various free digital elevation models (DEMs) available online (SRTM, ASTER, ALOS), the spatial resolution of which is $\sim 30 \mathrm{~m}$. This resolution is not enough for detailed flood mapping in mountainous areas.

Georisk CJSC provided linear shapefile of elevation isolines of 1:10,000 scale. From this shapefile, $5 \mathrm{~m}$ resolution DEM of studied area was calculated using Topo to Raster interpolation tool of ArcGIS Spatial Analyst toolbox (Figure 3):

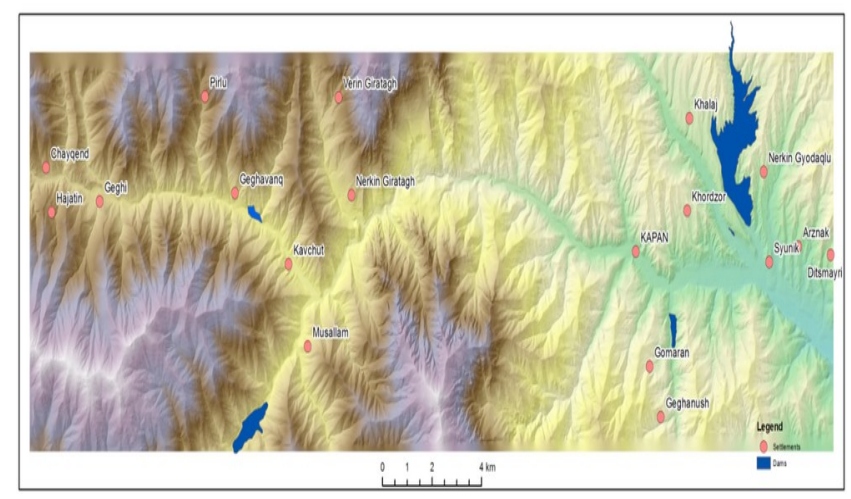

Figure 3. 5m DEM of Studied Area 
Geomorphometric parameters (slope, aspect and shaded relief) were derived from DEM and by using ArcHydro Tools, raster layers were calculated from the DEM (Filled DEM (hydrologically-corrected); Flow Direction; Flow Accumulation; Streams (defined and segmented); Catchments GRID).

Catchment polygon has been created based on the layers created and drainage line vector layers were obtained. A detailed land-cover and land-use maps have been created using the European Space Agency (ESA) and the European Commission services [6]. For open water (including Geghi reservoir) and tailing ponds Sentinel-1 (SAR) data was used. After obtaining the results of open water and tailing ponds then they were superimposed on the other classes. The final map is shown in the Figure 4.

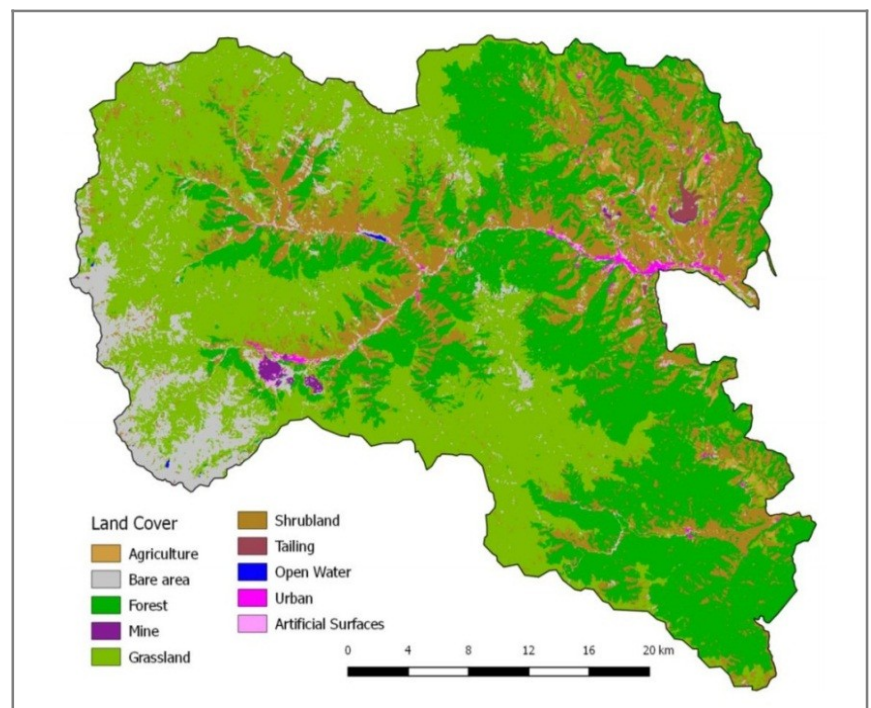

Figure 4. Land-cover and land-use map of Voghji river basin

\section{DESKTOP APPLICATION FOR FLOOD HAZARD AND RISK IN ARMENIA}

Based on the flood maps presenting different scenarios of water spill from the dam break a specially developed open source desktop tool has been created. Its architecture is based on model designed within the ALTER consortia with no use of commercial software. The application is mainly based on open source GIS software; server part for the dynamic events, JavaScript and its libraries and frameworks. The tools implemented are open source software solutions such as: Geoserver, Qgis, Web App Builder, Boundless WEBSDK, OpenLayers.

Geoserver allows the user to display spatial information to the world; \newline

QGIS is a professional GIS (Geographic Information System) cross-platform application that is Free and Open Source Software (FOSS);

Web App Builder is a plugin for QGIS that allows easy creation of web applications;
Boundless WEBSDK which provides tools for easy-tobuild JavaScript-based web mapping applications; \newline

OpenLayers is an open-source JavaScript library for displaying map data in web browsers.

It includes different features and tools that may lead to faster response and easier way of taking decisions in flood event cases.

The application has the function to visualize the most vulnerable buildings (Figure 5). It includes different scenarios that can be analyzed in operational room and by its tools can support better management of the current and future situation in cases of flood events. It is focused on visualization of high waves coming after dam break in cases of failure.

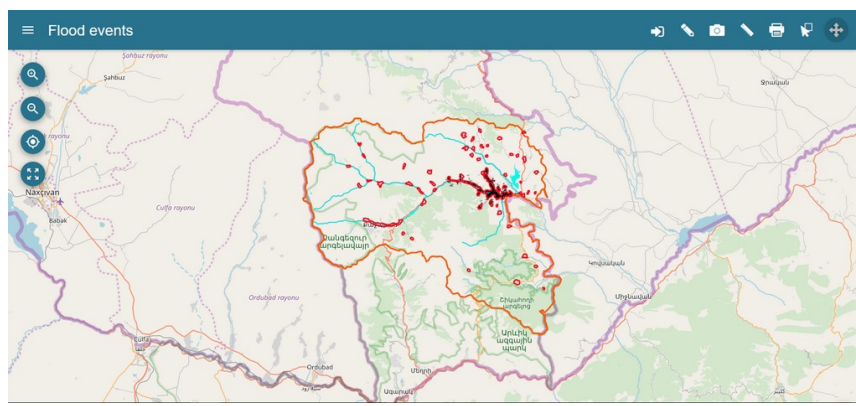

Figure 5. Application main screen

The application has the ability of switching the predefined layers and the base map layers. The predefined layers have a very rich data by turning them off or on. Users can easily make analysis of the risks in cases of flood events. It includes different scenarios of the water spread in support of better decision making and faster resource allocation. Layers can be downloaded as geojson files. Geolocation of team members on the field is available for the users.

The base map layers are including Street map, Satellite map, Shaded relief map and NatGeo map which can be used in operational room analysis.

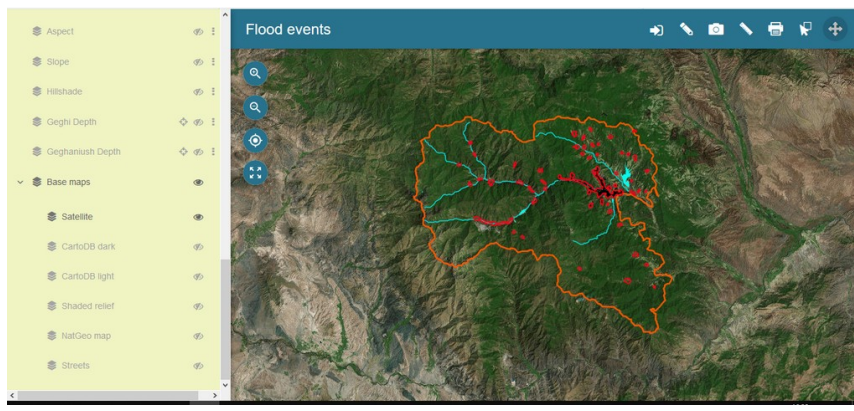

Figure 6. Layers list

Draw feature tool can mark the zone of interest (Figure 6) by polygon or line which will be visualized and be seen in the operational room in real time. 
The Popup feature visualizes information about the vulnerable buildings such as: schools, kindergartens and others (Figure 7).

The export feature can save maps with new data as picture format files. This feature can be used in future data analysis.

Measure and distance options can be used to measure the distances and also can measure the size of the focused area.

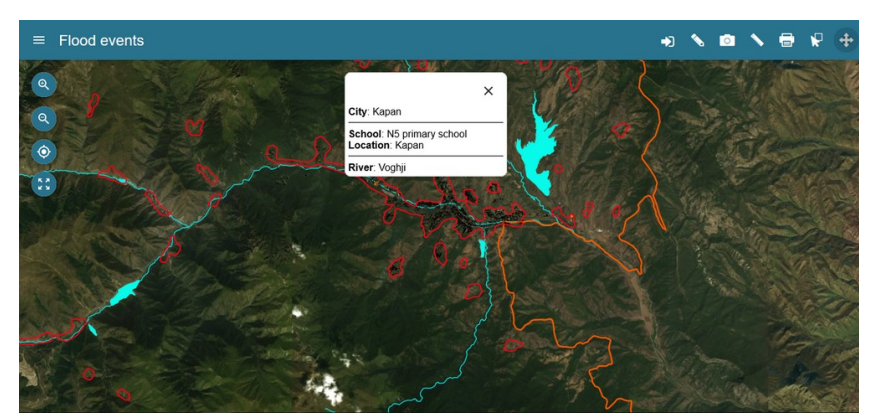

Figure 7. Application Popup

The application provides connection to the current weather forecast via openweather with detailed information about the current or future weather conditions. It is connected to EFAS emergency management service which provide extra satellite data about current conditions.

\section{CONCLUSION}

GIS raster layers of flood inundation zones and depths, as well as tables of simulated dam break characteristics for Geghi Reservoir and Geghanoush TSF Dams were developed for three failure scenarios: full failure, half failure and $10 \%$ failure. Maximum depth of the flooding, maximum absolute altitude, flooding time, maximum flow discharge and velocity in given cross-section and other parameters were calculated. Based on the analysis and discussions of these results open source web-GIS visualization tool has been developed and implemented for testing the areas of the research work.

\section{REFERENCES}

[1] Georisk CJSC (2017) Assessment of the Multi-Component Risk Determined by the Maximum Seismic Impact on the Kapan City (Multi-Hazard City Scenario). Project \# ARM 10-0000005849, Final Report.

[2] Gevorgyan A., Minasyan R., Khondkaryan V., Antonyan A. (2014) The Prediction of Possible Flooding of the Territory as a Result of the Accident of the Geghi Reservoir Dam.

[3] Costa, John E., 1985. Floods from Dam Failures. United States Department of the Interior, Geological Survey, Open-File Report 85560 , Denver, CO.

[4] Atallah, Tony A., 2002. A Review on Dams and Breach Parameters Estimation. Master of Science in Hydrosystems Engineering, Virginia Polytechnic Institute \& State University, Blacksburg, VA, January 2002.

[5] Wahl, Tony L., "Dam Breach Modeling - an Overview of Analysis Methods". Joint Federal Interagency Conference on Sedimentation and Hydrologic Modeling. June 27 - July 1, 2010, Las Vegas, NV.

[6] Schlaffer S., Harutyunyan A. (2018) Working Paper: LCLU Voghji River Basin AUA Acopian Center for the Environment, AUA GIS and Remote Sensing Lab. 